\title{
The Influence of Social Environment on Employees' Work Life Balance in the Insurance Industry
}

\author{
Florence Githinji \& Dr Sussy Wekesa
}

Department of Entrepreneurship, Procurement \& Management, Jomo Kenyatta University of Agriculture \& Technology P.O. BOX 62000-00200 Nairobi, Kenya, Florence Githinji P.O. Box 12471-00100 Nairobi.

\begin{abstract}
The insurance sector is one of the largest growing service providers in the country. Due to global dynamics and changes in the environment, emerging trends have continued to be experienced in the industry which employs a large number of workers who are unable to balance between work life and personal life. According to the African Reinsurance Corporation, the year's 2013 and 2014 the insurance industry experienced major changes due to emerging trends which led to low insurance uptake which in turn increased the number of casualties for insurers firms and reinsuring companies in Nairobi. There was an increase in acquisitions and mergers in this industry so as to remain afloat and competitive. This study explored the Influence of Social Environment on Employees' Work Life Balance in the Insurance Industry. Apparently, very little research has been carried out in Kenya on this. The study drew samples from Nairobi County as the area is more open to research, and is the concentration centre for most insurance companies in Kenya. In this research 47 insurance companies in Nairobi County were studied. All insurance companies were covered so as to ensure that a high level of data was accurately obtained. Data was collected using questionnaires which had both open and closed ended questions. SPSS was used to ensure accurate evaluation and presentation. The study found that influence of social environment positively influences the employees' work life balance in the insurance industry. The study recommends that the management should consider social environment in their organisation which will help to improve home life interfere with responsibilities at work such as getting to work on time.
\end{abstract}

Keywords - Employees, Social Environment, Work Life Balance, Insurance, motivation

\section{INTRODUCTION}

According to Anwar (2008), insurance is as an agreement whereby an insurer undertakes to pay a policyholder an amount of money on the occurrence of a specified event. The specified event must have some element of uncertainty about it. Globally, insurance industry is regulated by International Association of Insurance Supervisors (IAIS). IAIS was established in 1994 to harmonize international insurance regulatory requirements and acts as a forum for insurance industries to discuss developments in the insurance sector and topics that affect insurance regulation generally (Tromp, 2008). Countries in the East African Region have recently agreed in the EAC (East African Community) to harmonize their insurance regulations to be in line with the insurance principles (Okwera, 2014). Social issues such as new demographics of prolonged life expectancy, an increase in elderly people, falling birth rate and expectation of high level healthcare and pensions makes big pressure on social security system and have negatively affected economic growth (Ojo, 2012). Over the past few years, addressing work-life balance has become increasingly obvious and critical. Swami (2007) defined work life balance as a practice that is concerned with providing scope for employees to balance their work with responsibilities and interests they have outside work. Work Life Balance enables employees to reconcile the competing claims of work and home by meeting their own needs as well as those of their employers. In current economic times, organizations are hard pressed for higher productivity and need employees with improved work-life balance as employees with better work-life balance will contribute more meaningfully towards the organizational growth and success (Naithani, 2010).

\section{STATEMENT OF THE PROBLEM}

The year 2014 saw mergers and acquisitions in the following organizations: Saham Group of Morocco acquire a majority stake of $66.7 \%$ in Mercantile Insurance Company Limited in April 2014, Union insurance of Mauritius acquired a controlling stake of $66 \%$ in Phoenix East Africa Company Limited in May 2014, Prudential Plc, UK made a return to Kenya by wholly acquiring Shield Assurance Company in September 2014. The move by insurance firms to acquire and merge also led to changes in the social environment which led to new organizational restructuring, job re-engineering and ultimately downsizing of employees who had come of age hence retiring and rendering employees redundant. These changes increased pressure on employees, in 
terms of adjusting to the change itself and coping with its resulting effects. There was increased pressure from workloads and a need to develop new skills. According to Ngang'a (2010) in the study on international nongovernmental organizations in the health sector in Kenya he recommended that organization need to adopt quality work life balance practices. The study proposed that work life balance initiatives includes compressed work hours, alternative work hours, flexible working arrangements, job sharing, childcare facilities, wellness programmes and telecommuting. The research observed an increase in employee motivation and productivity in the organizations that adopted these work life balance initiatives. According to Kamau et al., (2013) the effect of work life balance practices had an effect on employee job performance at Eco Bank Kenya concluded that flexible working arrangements improve employee job performance. Further, the presence of employee assistance programmes at ECO Bank improved employee performance, as well as employee attendance rates. Leave policies were found to impact positively on the employees work performance by reduced work-related stress

\section{LITERATURE REVIEW}

There are two theories that the researcher used to for the literature review of the study, which are The Ecological System Theory and The Spill over theory. The Ecological System Theory was first published by Urie Bronfenbrenner (1979), a famous psychologist in order to find out why people behave differently in comparison to other members in the family; at school and in relation to colleagues whilst in the workplace. The theory encompasses the process which psychologists can analyze a person under different environmental conditions that one encounters. According to Sven (2007), the chronosystem includes the transitions and shifts in one's lifespan involving socio historical contexts that may influence a person like conflicts at home affects a person's relationships leading to constrained interaction between and within the family as well as friends and extended family as well as colleagues. The environment is not static and does not affect people in the same way; rather it is dynamic and ever changing. Spill over theory was first mentioned by Pleck (1977) when he analyzed workfamily role systems and the spill over into both domains work life and family life (Naithani, 2010). Spill over is a process upon which experiences in one role affect experiences in the other, rendering the roles more similar such as emotions, attitudes; skills and behaviour that are established at work into the family and those established in the family into work. If work-family dynamics leave little room for flexibility, there is negative spill over in terms of time, energy and behavior.

\subsection{Conceptual Framework}

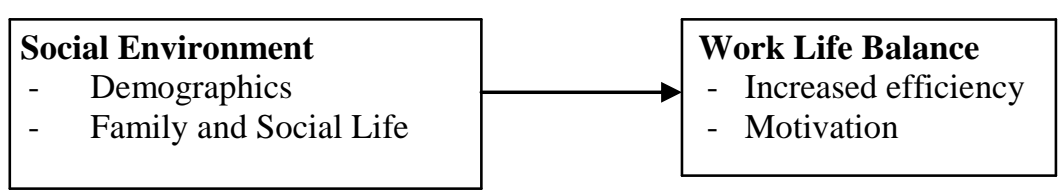

Independent Variable

\section{Dependent Variable}

Figure 1

According to Carlson et al., (2010) work-family enrichment is often involved with job and family involvement. It needs to be enriched so as to improve the quality of life in another role; the quality of life is likely also to heighten satisfaction. However, this relationship is mediated by positive mood. Masood et al., (2012) identified that gender variable has significant impact on organization critical factors for maintaining the work-life balance. Both men and women juggle their work with their household and caring responsibilities which has led to negative consequences of work-family conflict. Parental responsibilities of working couples add to the issue of work-family conflict. This is because the couples have to deal with demands and less control over their time Duxbury \& Higgins (2007). Workers supported by both family friendly organization norms and supportive co-workers were more likely to report higher levels of family satisfaction while having an understanding supervisor increased marital satisfaction (Hill, 2005). As age progresses men and women get married creating more responsibilities at home to handle that affect their work life balance. As their length of service increases their responsibilities at their work place also increases, as they move up the career ladder. When it comes to family and social life, employees should learn how to slow down, share work load, negotiate change with employer when they experience burnout situations, they should learn to let go and set boundaries. Providing employees with benefits such as, child care or eldercare facilities helps reduce financial burden related to childcare or eldercare issues. 


\section{RESEARCH METHODOLOGY}

A quality research design is dependent on the interaction between data collection and data analysis to allow for meaning to be explored and clarified (Saunders et al., 2012). This study used cross sectional survey design and descriptive research design methods. A survey is an attempt to collect data from members of a population in order to determine the current status of that population with respect to one or more variables. Cross-sectional research involves using different groups of people who differ in the variable of interest but share other characteristics, such as socioeconomic status, educational background, and ethnicity (Sekaran et al., 2010). Orodho (2003) and Kothari (2004) describe a descriptive survey design as a design that sought to portray accurately the characteristics of a particular individual, situation or a group. The target population of this study was all the insurance companies in Nairobi County. According to the IRA in 2014 there were 47 insurance companies who have their head offices in Nairobi County and focus were on these companies. Sampling method was used due to its viability to identify respondents who participated in the study. The information was obtained by collecting data through the administration of questionnaires. The researcher used this method to validate the results of the respondents obtained. Drop and pick method was used for data collection. Before the actual study, a pilot study was conducted. According to Orodho (2003), a pilot test helps to test the reliability and validity of data collection instruments. The data obtained was analyzed using both quantitative and qualitative approaches. The researcher used bar charts, statistical computations, calculations and oral narratives based on subjective summary of phenomena were put to great use during the analysis of data.

\section{Research Findings}

The target population of this study was all the insurance companies which were 47 in Nairobi County. The study targeted a sample size of 47 respondents in which 42 out of the total 47 filled in and handed in their questionnaires. From the data collected the total actual response percentage was $89.4 \%$ while the remaining $10.6 \%$ did not return their questionnaires on time.

The researcher analyzed the data collected and presented both quantitative and qualitative as follows:

\subsection{Demographic Information}

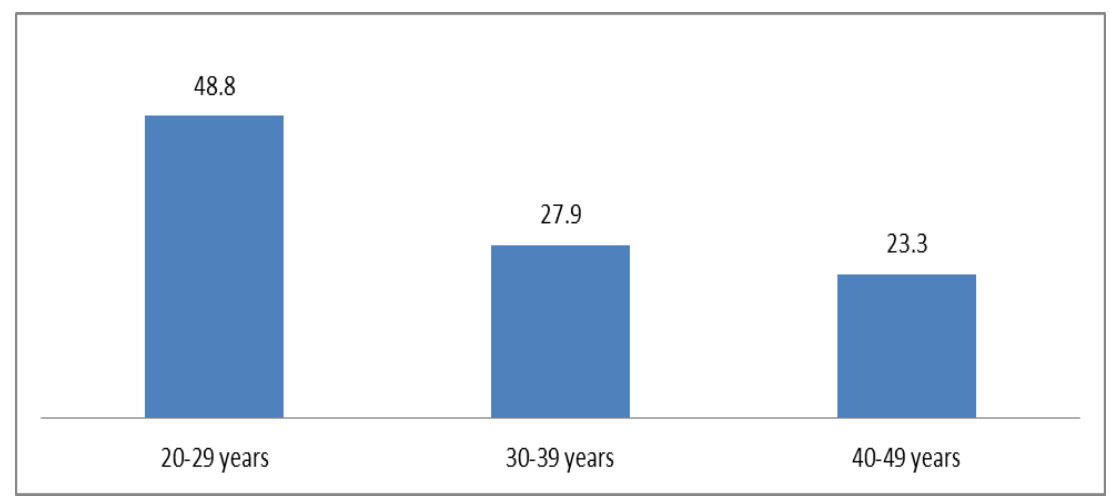

Figure 2: Age of the Respondents

From the findings on Fig.2, majority of the respondents as shown by $48.8 \%$ of the respondents were aged between 20-29 years which is the most productive bracket, $27.9 \%$ of the of the respondents also indicated they were aged between 30-39 years a bracket that has more family responsibilities which affect their productivity, and $23.3 \%$ of the respondents indicated were aged between $40-49$ years. None of the respondents were aged above 50 years. This is an indication that respondents were well distributed in terms of their ages.

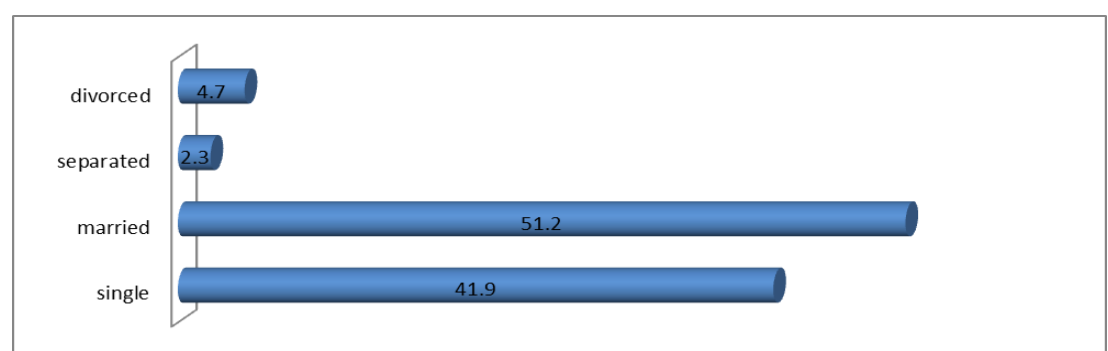

Figure 3: Marital Status of the Respondents 
Majority of the respondents as shown by $51.2 \%$ of the respondents were married, $41.9 \%$ of the respondents indicated they were single, and $4.7 \%$ of the respondents indicated they were divorced with $2.3 \%$ of the respondents indicating that they were separated as per the Fig. 3 above.

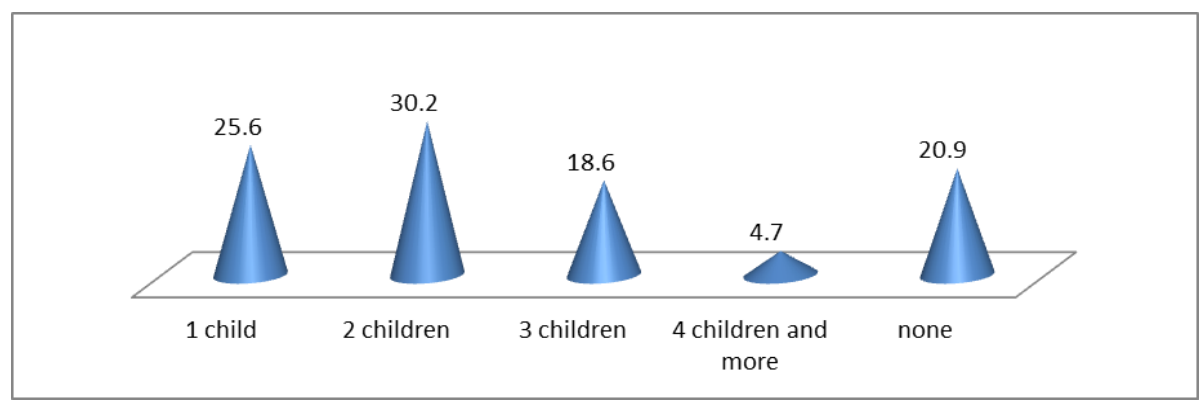

Figure 4: Number of Children of the Respondents

From Fig. 4 above majority of the respondents as shown by $30.2 \%$ indicated that they had 2 children, $25.6 \%$ indicated that they had 1 child whereas $20.9 \%$ indicated that they had no children, $18.6 \%$ indicated that they had 3 children and $4.7 \%$ indicated having 4 children and more. This is an indication that respondents would be capable to respond to the questions with ease as they have dual roles in the workplace as well as take care of children at home.

\subsection{Descriptive Statistics}

Descriptive statistics is the term given to the analysis of data that helps describe, show and summarize data in a simple meaningful way such that, patterns might emerge from the data Kothari (2004).

Table 1: Social Environment Effect on Work Life Balance

\begin{tabular}{|l|l|l|}
\hline & & \\
\hline Do social environmental factors such as demographics affect work life balance & 1.00 & 0.00 \\
\hline Extent at which home life interfere with responsibilities at work such as getting to work on time & 3.28 & 1.45 \\
\hline Extent to which work related duties make changes to your plans and activities with family and friends & 3.02 & 0.96 \\
\hline Whether at workplace you have good friends whom you share your worries and problems & 1.16 & 0.37 \\
\hline If there are policies that address gender balance equality in the company & 1.21 & 0.41 \\
\hline If the organization has a clear policy on different types of leave & 1.16 & 0.37 \\
\hline
\end{tabular}

On the respondent's level of agreement with the statements on the Table 1 above, assessing social environment as an influence of emerging trends on employees' work life balance in the insurance industry in Nairobi County, the study found out that social environmental factors such as demographics affect work life balance as shown by a mean of 1.00. Majority of the respondents agreed that a mean of 3.28 is that home life interfere with responsibilities at work such as getting to work on time, it also shows the extent to which work related duties make changes to your plans and activities with family and friends as shown by a mean of 3.02. There are policies that address gender balance equality in the company as shown by a mean of 1.21 , that the organization has a clear policy on different types of leave as shown by a mean of 1.16 that at workplace they have good friends whom they share their worries and problems as shown by a mean of 1.16 .

\subsection{Regression Analysis}

Regression analysis presents the results of the data collection process that involves classification, analysis, and interpretation of numerical facts or data.

Table 2: Social Environment in relation to Increased Efficiency

\begin{tabular}{|c|c|c|c|c|}
\hline Model & R & R Square & Adjusted R Square & Std. Error of the Estimate \\
\hline 1 & $.927 \mathrm{a}$ & 0.859 & 0.841 & 0.2582 \\
\hline a. & Predictors: (Constant), Demographics, Family and Social Life \\
\hline b. & Dependent Variable: Increased Efficiency \\
\hline
\end{tabular}


Adjusted R squared is coefficient of determination which tells us the variation in the dependent variable due to changes in the independent variable, from the findings in the above table the value of adjusted $\mathrm{R}$ squared was 0.841 an indication that there was variation of $84.1 \%$ on increased efficiency due to changes in social environment at $95 \%$ confidence interval. This shows that $84.1 \%$ changes in work efficiency could be account for social environment; $\mathrm{R}$ is the correlation coefficient which shows the relationship between the study variables, from the findings shown in the table above there was a strong positive relationship between the study variables as shown by 0.927 .

Table 3: Social Environment in relation to Motivation

\begin{tabular}{|r|l|c|c|r|}
\hline Model & \multicolumn{1}{|c|}{ R } & R Square & Adjusted R Square & Std. Error of the Estimate \\
\hline 1 & $0.804 a$ & 0.647 & 0.624 & 5.14633 \\
\hline a. $\quad$ Predictors: (Constant), Demographics, Family and Social Life \\
\hline b. Dependent Variable: Motivation \\
\hline
\end{tabular}

From the findings in the above table 3, the value of adjusted $\mathrm{R}$ squared was 0.624 an indication that there was variation of $62.4 \%$ on motivation due to changes in social environment at $95 \%$ confidence interval. This shows that $62.4 \%$ changes in work life balance could be account for social environment; $\mathrm{R}$ is the correlation coefficient which shows the relationship between the study variables, from the findings shown in the table above there was a moderate positive relationship between the study variables as shown by 0.647 .

Table 4: Regression Coefficients

\begin{tabular}{|l|l|c|c|c|c|c|}
\hline Model & & \multicolumn{2}{|c|}{$\begin{array}{c}\text { Unstandardized } \\
\text { Coefficients }\end{array}$} & $\begin{array}{c}\text { Standardized } \\
\text { Coefficients }\end{array}$ & T \\
\hline \multirow{2}{*}{1} & & $\mathrm{~B}$ & Std. Error & \multicolumn{2}{|c|}{ Beta } & \\
\cline { 2 - 7 } & Constant & .417 & .984 & .42 & .101 & .017 \\
\cline { 2 - 7 } & Social Environment & .695 & .441 & .029 & 3.093 \\
\hline
\end{tabular}

$\mathrm{p}<0.05$, independent variable; social environment

From the above regression it was revealed that social environment of constant zero, work life balance would be 0.417 , a unit increase in social environment would lead to increase in work life balance by factors of 0.695 . The regression equation is: $\mathrm{Y}=0.417+0.695 \mathrm{X}_{1}+\varepsilon$, whereby;

$\mathrm{Y}=$ Work Life Balance

$\beta \mathrm{o}=$ Constant

$\mathrm{X}_{1}=$ Social Environment

$\varepsilon=$ Error Term

\subsection{Findings}

\subsubsection{Social Environment}

The study found out the extent at which home life interfere with responsibilities at work such as getting to work on time, the extent to which work related duties make changes to your plans and activities with family and friends, that there are policies that address gender balance equality in the company, that the organization has a clear policy on different types of leave that at workplace they have good friends whom they share their worries and problems and that social environmental factors such as demographics affect work life balance. The findings of the study were in line with Carlson et al., (2010) who states that work-family enrichment is often involved with job and family involvement. It is also line with Masood et al., (2012) who identified that gender variable has significant impact on organization critical factors for maintaining the work-life balance.

\section{CONCLUSION}

On influence of social environment on employees' work life balance in the insurance industry, the study found that influence of family life, and work life positively influence the employees' work life balance in the insurance industry. Thus the study concludes that social environment has a positive influence on the employees' work life balance in the insurance industry. From the findings and conclusion on the influence of flexible working hours on employees' work life balance in the insurance industry, the study found that flexible working hours positively affect employees' work life balance in the insurance industry. 


\section{ACKNOWLEDGEMENTS}

I would like to extend my gratitude to the Almighty God for providing me with strength; knowledge and vitality that helped make this project a reality. I would wish to express my sincere gratitude to my Supervisor, Dr. Suzzy Wekesa for her scholarly support, patience, guidance; selfless dedication and encouragement in the planning, development and making this project a reality. It is without a doubt that her perpetual sacrifice; constructive criticism and comments shaped this report. Finally, I acknowledge the contribution of my colleagues and classmates, and more specifically Esther Mwangi and Purity Munyiri for the constructive meetings we had outside the institution, their critics and positive input.

\section{REFERENCES}

[1] Anwar, Habiba (2008). Islamic Economic Environment: A Guide for International Business and Investment. GMB Publishing Ltd., United Kingdom.

[2] Ojo, M. (2012). Insurance sector development and economic growth in Nigeria, African Journal of Business Management, 6(23), 7016-7023.

[3] Naithani, P. (2010). Overview of Work-life balance discourse and its relevance in current economic scenario. Asian Social Science, 6(6), 148-155.

[4] Ngang'a (2010). Quality of work Life Practices among International Non-Governmental Organisations in the Health Sector in Kenya

[5] Duxbury, L., Dyke,l. and Lam, n. (2000), Managing High Tech Employees, Carswell Press, Toronto.

[6] Saunders, M., Lewis, P., \& Thornhill, A. (2012) Research Methods for Business Students. Harlow; Pearson.

[7] Sekaran, U., \& Bougie, R. (2010). Research Methods for Business: A Skill Building Approach (5th Ed.). London: John Willey \& Sons.

[8] Orodho AJ (2003). Essentials of Educational and Social Science. Research Method. Qualitative and Quantitative Approaches Nairobi: Acts Press.

[9] Kothari C (2004). Research Methodology: Methods and Techniques, 2nd edition. New age International Publishers, New Delhi, India. 